\title{
PERAN SNOUCK HURGRONJE DALAM MERANCANG SISTEM PENDIDIKAN SEKULER DI INDONESIA DAN DAMPAKNYA BAGI KAUM PRIBUMI ISLAM
}

\author{
Irwan Abbas
}

FKIP dan Ilmu Budaya Universitas Khairun Ternate Email: irwanabbas@gmail.com

\section{Ronny Mahmuddin}

Sekolah Tinggi Ilmu Bahasa Arab (STIBA) Makassar

Email : ronnymahmuddin@gmail.com

\section{Hasnidar}

Lembaga Studi Ilmu Peradaban Islam (LSIPI) Maluku Utara

Email :

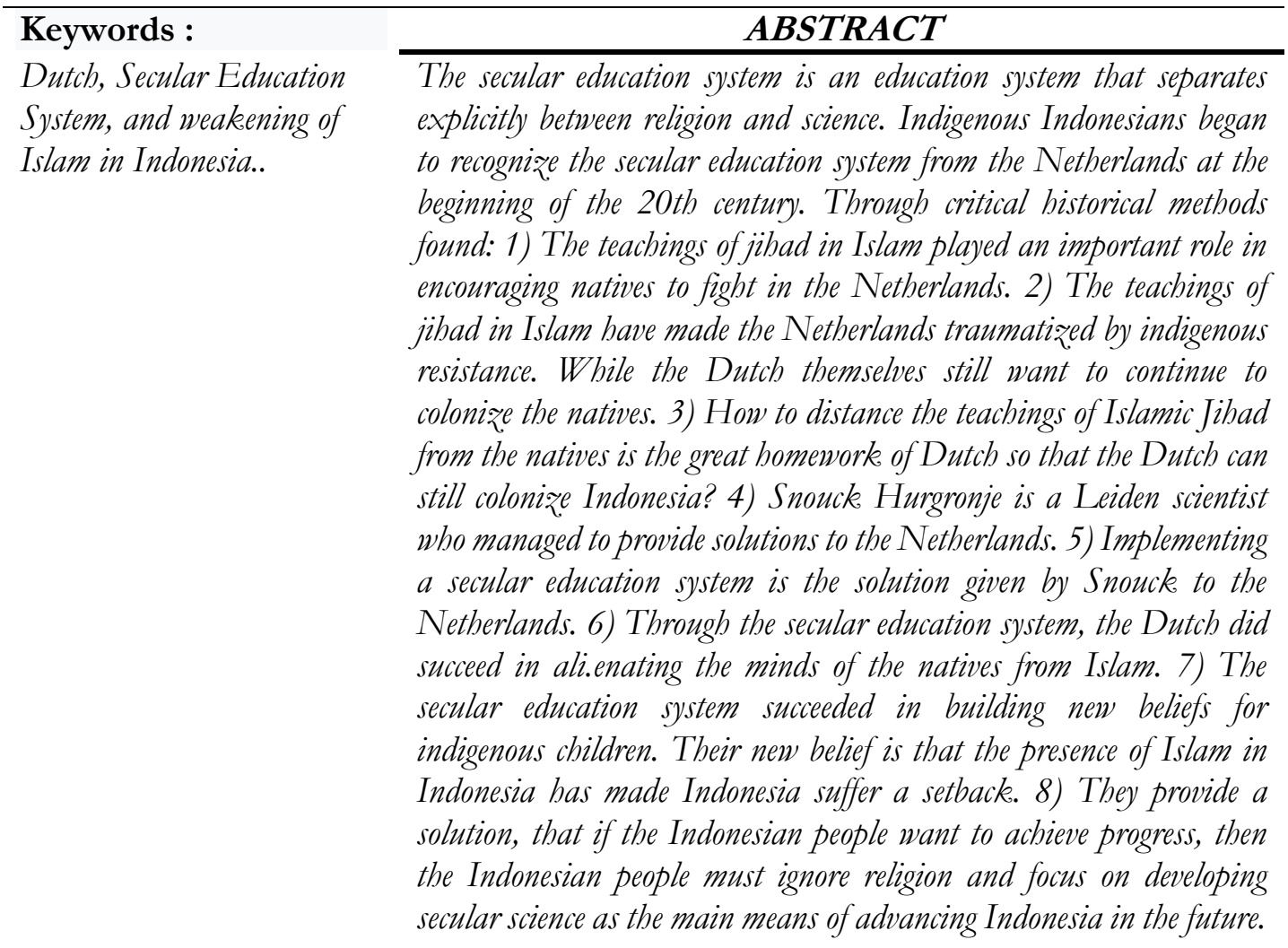


NUKHBATUL 'ULUM : Jurnal Bidang Kajian Islam

Vol. 4, No. 2 (2018) : Hal. 135-144

Website: https://journal.stiba.ac.id

ISSN : 2685-7537 (online) 2338-5251 (Printed)

\section{PENDAHULUAN}

Islam adalah sebuah konsep hidup yang unggul dan sejarah sudah membuktikan keunggulannya. Umar bin Abdul Aziz merupakan salah seorang khalifah yang berhasil mewujudkan keunggulan Islam atas negara yang dipimpinnya. Umar bin Abdul Aziz hanya butuh waktu 2/ 1/2 tahun (30 bulan) untuk membangun negaranya menjadi Negara Ideal di atas ideologi Islam. Dalam waktu 2 1/2 tahun, Umar bin Abdul Aziz berhasil meningkatkan kebahagiaan, kesejahteraan dan kemajuan rakyat. Keberhasilan Umar bin Abdul Aziz dalam meningkatkan kebahagiaan rakyat dapat diukur dengan semakin menurunnya konflik sosial dan budaya. Umar bin Abdul Aziz berusaha mendengar dan memberikan sikap yang adil dalam menyelesaikan konflik sosial dan budaya yang diwariskan oleh khalifah sebelumnya. Keberhasilan Umar bin Abdul Aziz dalam meningkatkan kesejahteraan rakyat dapat diukur dari sulitnya ditemukan orang-orang miskin yang mau menerima zakat. ${ }^{1}$ Inilah bukti otentik, bahwa Islam adalah sebuah konsep hidup yang unggul yang sudah teruji oleh sejarah.

Negara Indonesia adalah negara mayoritas beragama Islam, mirip dengan keadaan rakyat ketika Umar bin Abdul Aziz menjadi khalifah. Sekarang mari kita bandingkan dengan realitas yang ada di dalam Negara Indonesia yang dibangun dengan

\footnotetext{
1 Penjelasan lebih jauh tentang keberhasilan Umar bin Abdul Aziz dalam mewujudkan negara ideal, lihat: Ali Muhammad Ash-Shallabi , Khalifah Pembaharu dari Bani Umayyah, (Jakarta: Pustaka Al Kutsar, 2007)

https://www.syariahmandiri.co.id/2012/12/offic
}

konsep Sekuler. Negara Indonesia sudah merdeka selama 73 tahun, namun Negara Indonesia masih jauh dari konsep Negara Ideal. Negara Indonesia hidup penuh dengan penderitaan yang memiriskan hati. Sebagian besar penduduk hidup dalam ketakutan dan keresahan, karena tingginya angka kriminalitas. Sebagian besar penduduknya, terutama kaum pribumi, masih hidup dalam kemiskinan, jauh dari tingkat kesejahteraan yang memadai. sebagian besar penduduk, terutama kaum pribuminya, masih jauh tertinggal dalam bidang ilmu pengetahuan. ${ }^{2}$ Para pemimpin Indonesia sudah jatuh pada kebiasaan korupsi. Perilaku korupsi bukan lagi milik individuindividu tertentu, namun perilaku korupsi sudah menjadi perilaku sosial. Perilaku pemimpin yang jatuh dalam perilaku korupsi sudah menembus angka 66,6\% dari 542 kepala daerah yang ada di Indonesia. Bupati sebanyak 415, walikota sebanyak 93 dan gubernur sebanyak 34 orang. ${ }^{3}$

Apa sebab utama yang membuat negara Indonesia yang sudah merdeka 73 tahun, namun negara Indonesia masih jauh dari negara ideal seperti yang dicapai oleh Khalifah Umar bin Abdul Aziz? Dr. Abdul Mannan sebagai Ketua Umum Pimpinan Pusat (Ketum PP) Hidayatullah memberikan jawaban. Ia mengatakan, bahwa Sistem Pendidikan Sekuler telah menjadi sebab utama atas lahirnya generasi Indonesia yang berkarakter negatif. Pada saat mengisi

\footnotetext{
e-boy-temukan-uang-rp-100-juta-agus-dankisah-umar-bin-khattab/

3 Usman Muhammad, Islam Solusi Terbaik Atas Problematika Manusia Modern, (Yogyakarta: Kalika, 2017), hlm. 262-263.
} 
Halaqah Peradaban di Masjid Ummul Quraa, Cilodong, Depok, Jawa Barat, Sabtu, 1 Februari 2014 yang lalu, ia menegaskan, bahwa "Korupsi adalah produk pendidikan sekuler". ${ }^{4}$ Menelusuri asal-usul sistem pendidikan sekuler di Indonesia menjadi sebuah studi yang sangat penting untuk memahami mengapa sistem pendidikan sekuler berhasil mendominasi sistem pendidikan di Indonesia.

Bagaimana kajian sejarah dalam melihat masalah ini? Kapan sistem pendidikan sekuler mulai diterapkan oleh Belanda di Indonesia dan betulkah "Sistem Pendidikan Sekuler" telah menjadi sumber utama bagi lahirnya generasi Indonesia yang berpikiran negatif pada Islam sebagai agama. sehingga menyebabkan generasi muda Indonesia moderen menjadi asing dengan Islam sebagai agamanya sendiri. pertanyaan-pertanyaan ini akan terjawab dengan sendirinya melalui kajian sejarah analisis di bawah ini.

Objek dari studi ini adalah menjelaskan peran Snuock Hurgronje dalam merancang sistem pendidikan sekuler di Indonesia dan dampaknya bagi kaum pribumi Islam pada awal abab ke-20. Metode yang digunakan dalam menjelaskan objek studi ini adalah metode sejarah kritis. Pendekatan yang digunakan adalah pendekatan studi mentalitas. Melalui studi mentalitas akan dipahami, bahwa sistem pendidikan sekuler yang memisahkan antara agama dan ilmu pengetahuan telah mendorong lahirnya mentalitas yang bermasalah bagi anak didik. Indikatornya adalah mereka menjadi berpikiran negatif pada agama dan bangga dengan pikiran-pikiran filsafat yang dimunculkan oleh para ahli

4

http://m.hidayatullah.com/berita/nasional/read/ filsafat. Di dalam pikiran mereka terbangun sebuah keyakinan baru, bahwa agama tidak diperlukan untuk membangun peradaban. Peradaban hanya bisa dibangun oleh para kaum filosof. Mereka menjadi suka membaca buku para filosof dan mengabaikan membaca buku-buku yang berbau agama.

\section{PEMBAHASAN}

\section{Islam Musuh Utama Belanda dalam Menjaga Hegemoni Politik dan Ekonomi di Indonesia}

Sumber menjelaskan, bahwa sistem pendidikan sekuler mulai dikembangkan oleh Belanda pada awal abad ke-20. Snouck Hurgronje memainkan peran sentral dalam mendorong Belanda menerapkan sistem pendidikan sekuler di Indonesia pada awal abad ke-20. Mengapa Belanda baru mulai berbicara pendidikan pada awal abad ke-20 dan siapa sosok Snouck Hurgronje yang memainkan peran sentral dalam mendorong Belanda menerapkan sistem pendidikan sekuler? Menjawab dua pertanyaan ini secara ilmiah akan sangat membantu kita dalam memahami mengapa sistem pendidikan sekuler diterapkan di Indonesia pada abad ke-20 dan mengapa alumni sistem pendidikan sekuler menjadi sosoksosok ilmuan yang memiliki persepsi yang begitu negatif pada agama dan sangat memuja pikiran-pikiran yang dihasilkan oleh pemikir Barat.

Belanda datang di Indonesia 1596. Sejak kedatangan Belanda di Indonesia harus berhdapan dengan kaum pribumi Indonesia yang sudah menerima Islam sebagai agama mereka. Di Indonesia sudah berdiri kesultanankesultanan Islam di berbagai wilayah 
Website: https://journal.stiba.ac.id

ISSN : 2685-7537 (online) 2338-5251 (Printed)

Indonesia. Selama 300 tahun, dari tahun 1596 sampai tahun 1900, Belanda sudah menjalani peperangan yang luar biasa dengan kaum pribumi. "Perjanjian politik dan ekonomi di atas todongan senjata", itulah strategi yang digunakan Belanda dalam menguasai wilayah Indonesia dari kesultanankesultanan Islam di Indonesia.

$$
\text { Islam sebagai agama }
$$
memainkan peran yang sangat penting dalam mendorong kaum pribumi melakukan perlawanan pada Belanda. Ayat ini merupakan panduan kaum pribumi Islam Indonesia dalam menyikapi perilaku kolonial Belanda.

"Perangilah dijalan Allah orangorang yang memerangi kamu, tetapi janganlah kamu melampaui batas, karena sesunggubnya Allah tidak menyukai orangorang yang melampani batas.” (Q.S. Al Baqarah (2), ayat 190). ${ }^{5}$

Kaum pribumi Islam menyebut orang Belanda dengan istilah "Kafir Londo". "Kafir Londo" sudah menindas dan memerangi kaum pribumi demi meraih hegemoni dalam bidang politik dan ekonomi. Atas dasar itu berperang melawan "Kafir Londo" adalah bagian dari jihad suci di jalan Allah. Bernard van Vlekke menyebutkan, bahwa istilah "Jihad" melawan "Kafir Londo" mulai ramai dibicarakan oleh kaum pribumi pada abad ke-17. ${ }^{\text {Perang melawan "Kafir }}$ Londo" ini berlangsung terus tanpa putus di wilayah Indonesia sampai akhir abad ke-19. Inilah yang kemudian membuat Belanda menjadi trauma dengan Islam sebagai agama. Islam sebagai agama telah menjadi

${ }^{5}$ Tim Redaksi Al Fatih, Al Fatih; Mushab Al Quran Tafsir per Kata Kode Arab, (Depok: Al Fatih, 2013). penghalang utama bagi Belanda dalam menguasai kaum pribumi Indonesia.

Bagaimana caranya agar Islam sebagai agama bisa dijauhkan dari kaum pribumi agar Islam sebagai agama tidak lagi menjadi spirit perlawanan menjadi pudar di kalangan kaum pribumi. Apabila Islam sebagai agama bisa dijauhkan dari pikiran kaum pribumi, maka Belanda akan mampu menundukkan dan menguasai kaum pribumi Indonesia. Inilah Pekerjaan Rumah (PR) besar yang harus dipecahkan oleh Belanda di Indonesia pada awal abad ke-20. PR besar ini berhasil dipecahkan oleh Snouck Hurgronje, seorang ilmuan busuk dari Leiden.

\section{Snouck Hurgronje: Ilmuan Busuk dari Leiden}

Ilmuan adalah orang yang ahli pada sebuah bidang ilmu pengetahuan. Sebagai seorang ahli, maka ilmuan harus bertangungjawab dalam memperbaiki peradaban agar manusia bisa menikmati peradaban yang positip, yaitu peradaban yang membahagiakan manusia secara individu dan secara sosial, serta aman secara ekologi. Inilah tugas normal seorang ilmuan dalam kehidupan manusia.

Dalam realitas sejarah, tidak semua ilmuan mampu melakukan tugas tersebut. Ada sebagian dari kaum ilmuan yang mengabdikan dirinya untuk membantu sebuah kekuasaan politik yang menindas. Inilah yang disebut dengan "ilmuan istana". Secara normatif, mereka itu disebut dengan "Ilmuan Busuk". Di dalam khasanah peradaban Islam, para ilmuan seperti ini disebut sebagai ulama Su', yaitu para

6 Bernard H.M. Vlekke, Nusantara: Sejarah Indonesia, (Jakarta: Gramedia, 2008), hlm. 203 dan dikutip pula oleh Luthfi Assyaukanie dalam Kata Pengantar buku yang sama. 
Website: https://journal.stiba.ac.id

ISSN : 2685-7537 (online) 2338-5251 (Printed)

ulama yang sibuk mencari kesenangan dunia dengan menjual kebenaran pada para penguasa yang menindas. Mereka sangat disenangi oleh penguasa yang menindas. Mereka diberikan gaji yang besar dan kehidupan yang mewah oleh penguasa yang menindas atas pengabdian mereka.

Snouck Hurgronje $\mathrm{e}^{7}$ merupakan salah satu ilmuan yang masuk ke dalam golongan para ilmuan Busuk, ilmuan istana, atau ulama Su'. Sebagai seorang ilmuan, ia harus memberikan penyadaran pada Belanda, bahwa menindas kaum pribumi adalah perilaku yang bertentangan dengan rasa keadilan dan rasa kemanusiaan. Snouck Hurgronje tidak melakukannya. Ia justru menjadi bagian penting dari Belanda dalam menindas kaum pribumi Indonesia.

Setelah berhasil melakukan penelitian atas kaum pribumi Indonesia, Snouck menjelaskan pada Belanda, bahwa Belanda tidak akan bisa menguasai kaum pribumi Indonesia dengan Strategi Perang. Cara terbaik untuk bisa menguasai Indonesia adalah dengan cara menerapkan "strategi pendidikan sekuler". Melalui "strategi pendidikan sekuler", maka Islam

7 Nama lengkapnya adalah Christian Snouck Hurgronje lahir pada tanggal 8 Februari 1857 di Oostterhout, Belanda. la merupakan anak keempat dari Pendeta J.J.Snouck Hurgronje. Snouck mendalami study dalam bidang ilmu budaya di Universitas Leiden. Sebagai seorang ilmuan, Snouck banyak dipengaruhi oleh "modernis Leiden", yaitu para ilmuan Leiden yang menganggap bahwa agama hanyalah sekedar kesadaran etis yang ada pada setiap manusia dan memandang bahwa dunia Barat memiliki superioritas terhadap dunia Timur. Dalam sejarah Indonesia, Snouck lebih dikenal sebagai "Arsitek Pelumpuhan Islam". Lathiful Khuluq, Strategi Belanda Melumpuhkan Islam: Biografi C. Snouck Hurgronje, (Yogyakarta: Pustaka Pelajar, 2002), hlm. 12. "Snouck Hurgronje, Siapa Dikau", dalam Era Muslim, "The Untold History: Konspirasi Penggelapan Sejarah di sebagai agama akan bisa dijauhkan dari kaum pribumi Indonesia. apabila ini berhasil dikembangkan dengan baik, maka di Indonesia akan lahir generasi muda sekuler, yaitu generasi muda yang memiliki persepsi negatif pada Islam sebagai agama dan memuja-muja pikiran yang dihasilkan oleh para ilmuan Barat. Hasil yang ingin dicapai dari "strategi pendidikan sekuler" adalah lahirnya sebuah model model masyarakat baru Indonesia yang tidak lagi membenci Belanda secara ideologi. Apabila tujuan ini bisa dicapai, maka Belanda akan lebih mudah dalam menjaga penjajahannya di Indonesia.

Secara konseptual, Islam tidak menganut sekulerisme. Islam sangat menghargai ilmu pengetahuan, sejauh ilmu pengetaahuan bersifat positip dan bisa mendukung lahirnya peradaban manusia yang lebih bersifat positip. Begitu berharganya ilmu pengetahuan di dalam Islam, maka Rasulullah mewajibkan setiap umat Islam, baik laki-laki, maupun perempuan untuk belajar menuntut ilmu. ${ }^{8} \quad$ Mengapa belajar menuntut ilmu diwajibkan, karena ilmu adalah kunci kebahagiaan manusia, di dunia dan di akhirat.

Indonesia (Pra Islam hingga abad ke-19), Edisi Koleksi 9. (Jakarta: Era Muslim Global Media, tanpa tahun). Darmawijaya \& Irwan Abbas, Islam dan Keutuhan Nasionalisme Indonesia; Perilaku Mulia Sultan Tidore, Zainal Abidin Syah dalam Berjuang dan Mempertahankan Keutuhan NKRI dari Strategi Pecah Belah Belanda setelah Indonesia Merdeka, dalam Ersis Warmansyah Abbas, Editor, Developing Education Based on Nationalisme Values, The Proceeding of Internasional Seminar Building Education Based on Nationalism Values, (Banjarmasin: FKIP Universitas Lambung Mangkurat, 2016).

${ }^{8}$ Rasulullah bersabda: "Menuntut ilmu adalah wajib bagi setiap muslim, baik laki-laki, maupun perempuan". (HR. Ibnu Majah), dalam Muhammad Faiz Almath, 1100 Hadis Terpilih; Sinar Ajaran Muhammad, (Jakarta: Gema Insani Press, 1991), hlm. 207. 
Website: https://journal.stiba.ac.id

ISSN : 2685-7537 (online) 2338-5251 (Printed)

Sumbangan Peradaban Islam

pada Dunia, karya Raghib As Sirjani adalah karya ilmiah yang sangat bagus untuk dibaca agar kita bisa memahami, bahwa Islam dan para ilmuan Islam telah berhasil membangun peradaban yang begitu agung di masa lalu dan itu adalah bukti bahwa Islam dan para ilmuan Islam telah memberikan sumbangan secara positip terhadap peradaban dunia. ${ }^{9}$

Ajaran Islam seperti inilah yang harus dilemahkan oleh Belanda. Menurut Snouck, "Strategi Pendidikan Sekuler" adalah strategi terbaik yang bisa digunakan untuk melemahkan ajaran Islam seperti itu. "Strategi Pendidikan Sekuler" harus diberikan pada anak-anak kaum priyayi abangan, karena secara agama, mereka ini masih menganut Islam secara simbolik. Pada anak-anak kaum priyayi abangan ini ditanamkan sebuah "Keyakinan Baru", bahwa jika kaum pribumi ingin maju seperti orang-orang Eropa, maka kaum pribumi harus menjadikan "cara berpikir sekuler" dalam meraih kemajuan.

Pada awal abad ke-20, Belanda sudah berhasil melahirkan Generasi Baru Indonesia yang Sekuler. Sebagai generasi sekuler mereka sudah meyakini, bahwa agama itu adalah sesuatu yang negatif dan untuk bisa meraih kemajuan, maka kita harus mengembangkan ilmu pengetahuan sekuler di Indonesia. "Keinginan untuk tetap menjajah agar Belanda

9 Raghib As Sirjani, Sumbangan Peradaban Islam pada Dunia, (Jakarta: Pustaka Al Kautsar, 2011). Buku yang tebalnya 862 halaman ini sangat layak untuk kita rujuk, karena kaya dengan data tentang keagungan peradaban Islam di masa lalu dalam upaya memperbaiki kondisi peradaban yang begitu rusak saat ini.

${ }^{10} \mathrm{dr}$. Wahidin Sudirohusodo lahir di pada tahun 1852 di desa Miati, 5 kilometer dari Yogyakarta. la berasal dari keluarga Priyayi desa. tetap bisa hidup senang dan mewah di atas kekayaan alam dan penderitaan rakyat Indonesia" adalah tujuan utama yang dicapai Belanda dengan menerapkan "Strategi Pendidikan Sekuler".

\section{Dampak Negatif Sistem Pendidikan Sekuler Bagi Kaum Pribumi Islam.}

Sumber memperlihatkan, bahwa "Sistem Pendidikan Sekuler" memang berhasil melahirkan generasi baru Indonesia yang berpikir secara sekuler. Mereka itu pada umumnya berasal dari anak-anak Priyayi Abangan. Anak-anak kaum pribumi yang melanjutkan studi di STOVIA, seperti dr. Wahidin Sudirohusodo, ${ }^{10}$ Sutomo, dan Gunawan Mangunkusumo adalah tiga generasi awal yang berhasil dikader oleh Belanda dengan sekulerisme. Setelah selesai dari STOVIA, mereka tampil menjadi sosok-sosok intelektual muda Jawa yang sangat berpengaruh. Mereka inilah yang mendirikan organisasi Boedi Oetomo pada tanggal 20 Mei 1908. ${ }^{11}$

Bagaimana pikiran mereka dengan Islam? Betulkah mereka itu sudah melihat Islam dengan cara yang negatif sebagaimana yang diinginkan oleh Belanda? Sumber-sumber cukup mendukung dalam menjawab pertanyaan ini. Sebagai alumni STOVIA, sosok dr. Wahidin Soediro Hoesodo merupakan sosok intelektual Jawa yana sangat disegani oleh teman-

\footnotetext{
la termasuk anak yang cerdas. Kecerdasannya membuat ia berhasil masuk ELS (Europesche Lagere School), sekolah khusus orang Eropa setelah dibantu oleh Frits Kohle, seorang pegawai pabpik gula di Sragen. Gamal Kamandoko, Boedi Oetomo; Awal Bangkitnya Kesadaran Bangsa, (Yogyakarta: MedPres, 2008), hlm. 31-33, dan 38.

11 Boedi Oetomo; Awal Bangkitnya Kesadaran Bangsa, hlm. 10.
} 
temannya. Soetomo dan Gunawan Mangunkusumo menempatkan $\mathrm{dr}$ Wahidin sebagai guru mereka. Mereka adalah para pendiri Boedi Oetomo, sebuah organisasi yang dijadikan sebagai tongggak kebangkitan Indonesia modern. ${ }^{12}$

Bagaimana sebenarnya pikiran dr. Wahidin Sudirohusodo sebagai seorang intelektual Jawa yang telah terperangkap dengan strategi politik sekulerisasi yang dirancang oleh Belanda dalam melemahkan dan menyingkirkan Islam dari pikiran kaum pribumi. Berikut ini kutipan atas pikiran-pikiran dr. Wahidin Sudirohusodo yang ditulis oleh Gamal Komandoko dalam buku, "Boedi Oetomo; Awal Bangkitnya Kesadaran Bangsa". Gamal Komandoko menulis: "Jawa, bagian utama dari kekuasaan kolonial Belanda di Hindia Belanda, menurut Wahidin Sudirohusodo telah mengalami begitu banyak kemunduran pada abad ke-16. Sebelumnya, bangsa Jawa telah mencapai kemajuan yang luar biasa, semisal telah mampu menghasilkan berbagai mahakarya bangunan yang menunjukkan ketinggian kebudayaan dan teknologi pada zaman HinduBudha. Keperkasaan bangsa Jawa yang ditunjukkan kerajaan Majapahit, juga begitu disegani hingga daerah kekuasaannya terbentang luas, meliputi seluruh Kepulauan Nusantara. Tumasik (Singapura) dan juga Semenanjung Melayu. Setelah zaman Hindu-Budha berlalu dan masuknya Islam, bangsa Jawa kemudian "tertidur" dan terus terlelap dalam "tidur"-nya hingga bangsa Belanda datang dan menguasai bangsa Jawa." 13

Kutipan di atas memberikan gambaran, bahwa dr. Wahidin

12 Boedi Oetomo; Awal Bangkitnya Kesadaran Bangsa,, hlm. 31
Sudirohusodo menyimpulkan hasil analisisnya tentang orang Jawa. Kesimpulannya ada dua, yaitu orang Jawa sebelum menguatnya Islam di Jawa telah memiliki kebudayaan yang tinggi. Benda-benda cagar budaya seperti candi Brobudur, candi Prambanan, dan berbagai teknologi lainnya adalah bukti nyata dari betapa tingginya kebudayaan Jawa sebelum Islam berkembang di Jawa. Kerajaan Hindu Majapahit adalah merupakan simbol kebesaran orang Jawa. Pada masa Majapahit, orang Jawa disegani oleh seluruh wilayah Nusantara, bahkan sampai di Singapura dan Semenanjung Melayu. Kekuasaan orang Jawa mulai menurun, setelah Islam berkembang di pulau Jawa. Runtuhnya Kerajaan Majapahit pada abad ke-15 dianggap oleh dr. Wahidin sebagai puncak kemunduran orang Jawa. Kemunduran itu berlangsung terus hingga Belanda datang menguasai Pulau Jawa.

Pada halaman 37-38, Gamal Komandoko menguatkan lagi kesimpulan dr. Wahidin. Ia menulis:

"Menurut Wahidin, masyarakat Jawa sebelum kedatangan Islam terbagi menjadi tiga golongan, yaitu: mereka yang masih taat menganut kepercayaan animisme, mereka yang memeluk Hinduisme, dan mereka yang tertarik dengan Budhisme. Penggolongan masyarakat Jawa tersebut berlaku hingga penyebaran Islam sekitar tahun 1500. Wahidin menyatakan abad ke-16 merupakan periode kemunduran bagi "bangsa" Jawa hingga kedatangan bangsa Belanda."

Pikiran dr. Wahidin yang ditulis kembali oleh Gamal Komandoko menguatkan pikiran dr. Wahidin pada kutipan yang pertama. Inti dari kedua

13 Boedi Oetomo; Awal Bangkitnya Kesadaran Bangsa,, hlm. 33 
kutipan ini adalah kehadiran Islam di pulau Jawa merupakan penyebab utama mundurnya budaya Jawa Hindu-Budha. Islam dituduh sebagai penyebab kemunduran Jawa, tapi disisi lain, Belanda yang datang dengan tujuan menjajah justru dijadikan sebagai cita-cita kemajuan. Ia mengatakan:

"Keberhasilan mengubah masyarakat Jawa secepatnya sangat erat hubungannya dengan kefasihan mereka berbahasa Belanda, "Mereka yang tidak bisa memahami bahasa Belanda tidak bisa berdiri di pantai kemajuan."

Pada kutipan ini, dengan tegas

Dr. Wahidin menyatakan, bahwa penguasaan bahasa Belanda adalah cara terbaik meraih kemajuan dalam bidang ilmu pengetahuan. Bagi orang Jawa yang tidak bisa berbahasa Belanda maka mereka tidak akan bisa meraih kemajuan. Meninggalkan Islam dan menjadi Belanda secara pemikiran adalah jalan terbaik bagi kaum pribumi Indonesia untuk bisa meraih kemajuan.

\section{PENUTUP}

Islam sebagai agama yang benar, sempurna dan paripurna. Secara konseptual, Islam sebagai agama tidak mengenal istilah sekulerisme. Islam adalah panduan berpikir manusia dalam membangun kehidupan. Pada waktu Belanda datang dengan perilaku penjajahan, Islam sebagai agama telah memainkan peran yang sangat penting dalam memberikan panduan berpikir dan bertindak bagi kaum pribumi dalam menyikapi perilaku kolonial yang diterapkan oleh Belanda. Islam memberikan izin bagi kaum pribumi untuk "berjihad di jalan Allah" dalam menyikapi perilaku kolonial Belanda.

Belanda telah mengobarkan perang dengan kaum pribumi sekitar 300 tahun lebih, namun Belanda tetap tidak sepenuhnya berhasil dalam menguasai kaum pribumi. Ajaran jihad di dalam Islam telah menjadi "batu sandungan" bagi Belanda. Belanda menjadi trauma dan takut dengan Islam sebagai agama. Walaupun sudah trauma, ambisi untuk tetap menjajah kaum pribumi masih sangat besar. Bagaimana caranya agar Islam sebagai agama bisa dijauhkan dari kaum pribumi agar penjajahan tetap bisa berlangsung terus?

Kehadiran Snouck Hurgronje sebagai ilmuan Leiden di Indonesia menjelang akhir abad ke-19 berhasil memecahkan PR besar Belanda ini. Snouck memberikan sebuah strategi baru yang jauh lebih efektif. "Strategi Pendidikan Sekuler" adalah strategi yang diberikan oleh Snouck Hurngronje. Setelah diterapkan, Strategi Pendidikan Sekuler memang memberikan hasilnya yang luar biasa bagi Belanda.

Bagi kaum pribumi yang sudah mengikuti "Pendidikan Sekuler" yang diterapkan Belanda, mereka tampil menjadi orang-orang yang membenci Islam sebagai agamanya sendiri, seperti yang dialami oleh dr. Wahidin Soedirohusodo dan teman-temanya. "Dijajah, tanpa merasa dijajab" atau "Menjadi korban, tanpa merasa dikorbankan", itulah gambaran umum yang dialami oleh kaum pribumi Islam secara pemikiran setelah mengikuti "sistem pendidikan sekuler" yang diterapkan oleh Belanda.

Menjajah melalui "Sistem Pendidikan" sangat merusak kehidupan manusia. Cara kerjanya sangat halus, sama dengan cara kerja nyamuk dalam menghisap darah manusia. Melalui cara yang halus itu, penjajah ingin meraih keuntungan politik dan ekonomi. Apabila si korban sudah sadar, maka mereka 
akan meradang dan mengutuk si penjajah. Itulah perilaku para penjajah. Mereka ingin hidup enak di atas penderitaan orang lain. Segala cara akan mereka gunakan untuk bisa tetap menjajah, termasuk dengan menerapkan sistem pendidikan sekuler untuk menjauhkan kaum pribumi dari Islam sebagai agama perjuangan untuk keadilan dan kemanusiaan.

\section{DARTAR PUSTAKA}

Alam Solihin, M.. Perkembangan Pemikiran Filsafat dari Klasik bingga Modern, Bandung: Pustaka Setia 2007.

Ash-Shallabi, Ali Muhammad. Khalifah Pembaharu dari Bani Umayyah, Jakarta: Pustaka Al Kutsar, 2007.

As Sirjani, Raghib. Sumbangan Peradaban Islam pada Dunia, Jakarta: Pustaka Al Kautsar, 2011.

Bustami, Hepi Andi. Sejarah Para Khalifah, Jakarta: Pustaka Al Kautsar, 2008.

Darmawijaya. Kesultanan Islam Nusantara, Jakarta: Pustaka Al Kautsar, 2010.

Darmawijaya. Biografi Singkat 100

Tokoh Mulsim Nusantara, Ternate: Lepkhair, 2012.

Dzulhadi, Qosim Nursheha. Membongkar Kedok Liberalisme di Indonesia, Jakarta: Cakrawala Publishing, 2013.

Gie, Kwik Kian. Nasib Rakyat Indonesia dalam Era Kemerdekaan, Jakarta: Gramedia, 2016.

Khuluq, Lathiful. Strategi Belanda Melumpubkan Islam: Biografi C. Snouck Hurgronje, Yogyakarta: Pustaka Pelajar, 2002.

Kamandoko, Gamal Boedi Oetomo; Awal Bangkitnya Kesadaran Bangsa, Yogyakarta: MedPres, 2008.
Kartodirjo, Sartono. Pendekatan Ilmu Sosial Dalam Metodologi Sejarah, Yogyakarta: Ombak, 2016.

Muhammad, Usman. Islam Solusi Terbaik Atas Problematika Manusia Modern, Yogyakarta: Kalika, 2017.

Rais, Mohammad Amien. Agenda Mendesak Bangsa: Selamatkan Indonesia, Yogyakarta: PPSK Press, 2008.

Sholihan.

Modernitas,

Postmodernitas \& Agama, Semarang: Walisongo Press, 2008.

Tim Redaksi Al Fatih. Al Fatib; Mushab AlQuran Tafsirper Kata Kode Arab, Depok: Al Fatih, 2013..

Tim Redaksi. Kamus Besar Bahasa Indonesia, Edisi Ke-4, cetakan ke-7, Jakarta: Balai Pustaka, 2013.

Vlekke, Bernard H.M. Nusantara: Sejarah Indonesia, Jakarta: Gramedia, 2008.

Windy A. 100 Tokoh yang Mengubah Indonesia; Biografi Singkat Seratus Tokoh yang Paling Berpengaruh dalam Sejarah Indonesia di Abad 20,Yogyakarta: Narasi, 2005.

\section{Jurnal, Proseding \& Majalah}

Darmawijaya. Asal-usul Sekulerisme di Indonesia; SebuahAnalisis BerdasarkanTeori Diffusi Kebudayaan, dalam Jurnal Ilmiah Pendidikan dan Humaniora, Jember: Forum Komunikasi Ilmiah Dosen FKIP Universitas Jember dan Lembaga Pusat Pengkajian Pendidikan Sosial dan Ekonomi, Vol. 29 No. 1, April 2011).

Darmawijaya, Moh. Natsir: Pendekar Islam dari Minang, dalam Jurnal Sejarah danBudaya Walasuji, Vol. 2, No. 2, Desember 2011, (Makassar: BalaiPelestarian Sejarah dan Nilai Tradisional Makassar, 2011) 
Darmawijaya \& Irwan Abbas, Nilai-Nilai Kemanusiaan Sultan Nuku Dalam Berjuan Membebaskan Kesultanan Tidore dari Pengarub Kompeni dan Relevansinya Dengan Hukum Humaniter (Malang: Universitas Negeri Malang, 2015).

Darmawijaya, "Laa ilaaha ilallaah Ideologi Perubahan Holistik (Studi Kasus Perubahan Keperibadian Umar bin Khattab dari Peribadi Jahiliyah menjadi Peribadi Ilahiyah)." Dalam Jurnal Humano Vol. 7 No. 1. Ternate: LPPM Unkhair, 2016

Darmawijaya \& Irwan Abbas, Islam dan Keutuban Nasionalisme Indonesia; Perilaku Mulia Sultan Tidore, Zainal Abidin Syah dalam Berjuang dan Mempertahankan Keutuban NKRI dari Strategi Pecab Belah Belanda setelah Indonesia Merdeka, dalam Ersis Warmansyah Abbas, Editor, Developing Education Based on Nationalisme Values The Proceeding of Internasiona Seminar Building Education Based on Nationalis Value, (Banjarmasin:

FKIP Universitas Lambung Mangkurat, 2016).

Tim Penulis, "Snouck Hurgronje, Siapa Dikau", dalam Era Muslim, "The Untold History: Konspirasi Penggelapan Sejarah di Indonesia (Pra Islam hingga abad ke-19), Edisi Koleksi 9. (Jakarta: Era Muslim Global Media, tanpa tahun).

\section{Internet}

https://www.syariahmandiri.co.i d/2012/12/office-boy-temukan-uangrp-100-juta-agus-dan-kisah-umar-binkhattab/

http://m.hidayatullah.com/berit a/nasional/read/2014/02/01/15842/ abdul mannan-korupsi-produkpendidikan-sekuler.html\#.

Wan Mohd Saghir Abdullah, Perkembangan Ilmu Fiqh dan Tokob-Tokohnya di Asia Tenggara (Cet.1: Solo; CV. Ramadhani, 1985)

Wan Muhammad 'Ali bin 'Abd alRahman al-Kelantani, Zahrah al-Murid (Kota Bharu: alAhmadiyah Press, t.t.)

Zalila Sharif dan Jamilah Haji Ahmad, Sastera Melayu Tradisional (Kuala Lumpur: Dewan Bahasa dan Pustaka, 1993

Zulkifli Mohd Salleh, Hikayat Merong Mahawangsa (Kuala Lumpur: Dewan Bahasa dan Pustaka, 1972 